\title{
A Revista do Homem (Playboy) e a censura prévia na ditadura militar (1975-1976): entre a moral, os bons costumes e o homem contemporâneo
}

\author{
Raphael Diego Greenhalgh ${ }^{*}$ \\ ${ }^{1}$ Universidade de Brasília, Brasília/DF - Brasil \\ Carlos Henrique Juvêncio da Silva ${ }^{2 *}$ \\ ${ }^{2}$ Universidade Federal Fluminense, Niterói/RJ - Brasil
}

\section{RESUMO}

A Revista do Homem, atualmente revista Playboy, surge na década de 1970, um período conturbado para os meios de comunicação no Brasil. Pois, desde 1968, com a instituição do AI-5, a censura era um dos meios utilizados pelo regime ditatorial para o controle de opiniōes e, segundo seu discurso, preservaçáo da família à luz da moral e dos bons costumes. Sendo uma revista erótica, seu conteúdo teve que passar pelo crivo da censura oficial, tendo seu conteúdo afetado pelos cortes impostos. O objetivo deste artigo é compreender como os censores avaliavam o conteúdo veiculado n'A Revista do Homem e qual o impacto da censura prévia em suas ediçóes. Esta pesquisa descritiva e histórica com análise documental de 122 pareceres da censura buscou entender as minúcias do processo censório no período estudado. Conclui-se que apesar do esforço da DCDP no controle moral, existia certa permissividade, principalmente pelo entendimento de certos censores de que a revista tinha um público bem definido.

Palavras-chave: A Revista do Homem; censura; ditadura militar; erotismo; pornografia.

DOI: http://dx.doi.org/10.1590/2237-101X02204610

Artigo recebido em 6 de fevereiro de 2020 e aceito para publicação em 3 de junho de 2020.

* Pesquisador da Universidade de Brasília / Biblioteca Central, Brasília/DF - Brasil. E-mail: raphaeldgbiblio@gmail.com. ORCID: https://orcid.org/0000-0002-9625-5854.

** Professor da Universidade Federal Fluminense / Instituto de Artes e Comunicação Social / Departamento de Ciência da Informação, Niterói/RJ - Brasil. E-mail: carloshjuv@gmail.com. ORCID: https://orcid. org/0000-0003-2376-4823.

Pesquisa realizada com financiamento por bolsa de pós-doutoramento fornecida pela CAPES. 


\title{
The Revista do Homem (Playboy) and prior censorship during the military dictatorship, (1975-1976): between morality, good morals and contemporary man
}

\begin{abstract}
A Revista do Homem, an erotic magazine now known as Playboy, began publishing in Brazil in the 1970s, a troubled period for the Brazilian media, which the government had been censoring since 1968, with the institution of AI-5. Censorship was one of the methods the dictatorship used to control opinions and, according to the generals' speeches, preserve the family's good morals and customs. Because of its erotic content, the magazine had to pass the scrutiny of official censorship, which meant that tax cuts affected its production. The purpose of this article is to understand how officials evaluated the content published in A Revista do Homem and what is the impact of prior censorship had on its editions. This descriptive and historical research, with documentary analysis of 122 censorship opinions, seeks to understand the minutiae of the censorship process during the dictatorship. This article concludes that despite the DCDP's moral control efforts, there was a certain permissiveness, mainly due to certain censors understanding that the magazine had a well-defined audience.
\end{abstract}

Keywords: A Revista do Homem; censorship; eroticism; military dictatorship; pornography.

\section{A Revista do Homem (Playboy) y la censura previa en la Dictadura Militar (1975-1976): entre la moral, las buenas costumbres y el hombre contemporâneo}

\section{RESUMEN}

La Revista do Homem, actualmente revista Playboy, surge en la década de 1970, un periodo conturbado para los medios de comunicación de Brasil. Desde 1968, con la institución del AI-5, la censura era uno de los medios utilizados por el régimen dictatorial para el control de las opiniones y, según su discurso, la preservación de la familia a la luz de la moral y de las buenas costumbres. Siendo una revista erótica, su contenido tuvo que pasar por el tamiz de la censura oficial, teniendo su contenido afectado por los cortes impuestos. El objetivo de este artículo es comprender cómo los censuradores evaluaban el contenido vehiculado en la Revista do Homem y cuál fue el impacto de la censura previa en sus ediciones. Esta investigación descriptiva e histórica con análisis documental de 122 pareceres de la censura, buscó entender los pormenores del proceso de censura en el periodo estudiado. Se concluye que, a pesar del esfuerzo de la DCDP en el control moral, existía cierta permisividad, 
A Revista do Homem (Playboy) e a Censura prévia na ditadura militar (I975-I976):

ENTRE A MORAL, OS BONS COSTUMES E O HOMEM CONTEMPORÂNEO

Raphael Diego Greenhalgh e Carlos Henrique Juvêncio da Silva

principalmente por el entendimiento de ciertos censuradores de que la revista tenía un público bien definido.

Palabras clave: La Revista do Homem; censura; Dictadura Militar; Erotismo; Pornografía.

\section{Introdução}

A Revista do Homem surgiu em 1975, em um contexto histórico-político em que havia muito controle em relação às publicaçôes, sobretudo àquelas com conteúdo erótico, entretanto, a futura revista Playboy se manteve como o mais importante veículo de seu segmento, principalmente por se alinhar com os propósitos de crescimento econômico da ditadura militar.

O governo militar se apropria e modifica processos censórios advindos do Estado Novo, até em janeiro de 1970 editar o Decreto-lei 1.077, que permite oficialmente a censura prévia, visando evitar conteúdo que atentasse contra a moral e os bons costumes. Tendo como antepassado o Departamento de Imprensa e Propaganda (DIP), criado em 1939, a Divisão de Censura de Diversóes Públicas (DCDP) era o órgáo oficial que exercia a censura prévia ao conteúdo que se pretendia veicular no cinema, na televisão, no rádio, no teatro, nos livros e nas revistas.

Desde o seu início a revista teve que se submeter à censura prévia exercida pela DCDP. Logo, o objetivo deste artigo é compreender como os censores avaliavam o conteúdo veiculado pela A Revista do Homem e qual o impacto da censura prévia em suas ediçóes.

Metodologicamente, este artigo se ateve em analisar todos os pareceres desta Divisão sobre A Revista do Homem, constituindo-se em pesquisa descritiva e histórica, sendo realizada análise documental a partir de um levantamento quali-quantitativo no intuito de captar e entender as minúcias do processo censório no período analisado. Foram estudados 122 pareceres da censura prévia para A Revista do Homem, redigidos entre 3 de setembro de 1975 e 3 de janeiro de 1977. Esses pareceres estão no Arquivo Nacional (Coordenação Regional em Brasília - COREG), no fundo da DCDP, na seção Censura Prévia e na série Publicações, e correspondem às observaçóes dos censores para os números 03-19 da revista (17 números ao todo).

Com a análise dos pareceres foi possível identificar elementos característicos do processo censório nesse período, como o prazo médio para análise de um número, quantidade de censores atuantes em cada um deles, palavras e estruturas proibidas, subjetividade das análises, entre outros aspectos. 
A Revista do Homem (Playboy) e a Censura prévia na ditadura militar (I975-I976):

ENTRE A MORAL, OS BONS COSTUMES E O HOMEM CONTEMPORÂNEO

Raphael Diego Greenhalgh e Carlos Henrique Juvêncio da Silva

\section{A Revista do Homem}

A revista Playboy surgiu nos Estados Unidos em 1953 e teve em sua primeira capa a atriz Marilyn Monroe, sagrando-se desde o início um grande sucesso. No Brasil, uma primeira versão dessa publicação se dá com A Revista do Homem, com aparição em agosto de 1975, por iniciativa da Editora Abril (GIORDANO, 2012). O governo militar havia proibido a circulação da americana Playboy em 1973 e por este motivo seu nome foi omitido na edição brasileira, logo, por conta da censura, o seu título original só foi adotado apenas em julho de 1978 (RIBEIRO, 2016). Provavelmente o uso da marca Playboy na revista brasileira se deu devido à decisão judicial em favor da Editora Três, que teria o direito exclusivo sobre o nome Homem, alegando tê-lo registrado antes da concorrente (GIORDANO, 2012).

Em relação à nudez presente na revista, Ribeiro (2016) destaca que os números eram menores que em outras revistas eróticas, visto que o nu corresponderia a cerca de $20 \%$ em Homem, contrapondo-se às outras publicaçôes que apresentariam algo em torno de $70 \mathrm{a}$ $80 \%$ de nudez. Essa linha editorial alinhava-se ao ideal de leitores para a revista, com o propósito de atingir um público previsto de homens, heterossexuais, urbanos, modernos e de classe média/alta, conforme aponta Giordano (2012). Portanto, a revista apresentava uma nudez artística considerada de bom gosto, com as fotos assinadas, trazendo não só a beleza da mulher, mas ao mesmo tempo o ideal de mulher para o público da revista, mulheres profissionais e de sucesso, como atrizes, bailarinas, modelos etc. (GIORDANO, 2012).

O restante do conteúdo da revista ainda contava com matérias sobre política, religiáo, moda, ciência, literatura, arte, cinema, além de um espaço dedicado ao humor e à interação com o leitor a partir de cartas que estes enviavam à redação.

As divisóes das primeiras ediçóes contavam com seçóes que traziam pessoas conhecidas e respeitadas no meio cultural, e que responderiam a favor da revista, como o editorial de abertura ("Uma nova revista e seu primeiro número", por Victor Civita), "Ponto de Vista" (com a participação de diversas personalidades da TV, do esporte, do cinema e do movimento político e também feminista), "Assessoria" (perguntas e cartas com dúvidas dos leitores), "Cinema" (Francis Ford Coppola), "Futebol" (José Inácio Werneck), "Bazar" (com objetos para venda e preços de brinquedos, cintos de castidade, livros etc.), "Livros" (Roberto Drummond), "Artes Plásticas" (Pietro Maria Bardi), "Música Popular Brasileira" (Paulinho da Viola), "Música Erudita" (Isaac Karabtchevsky), "Dinheiro" (Paul Samuelson), "Ficção" (no primeiro número, um texto de Jorge Amado), "Mulher" (na primeira ediçáo, com a Valerie), "Artigo" (A crise monetária, por John Kenneth Galbraith), "Humor" (Sanguefrio, por Gahan Wilson), "Debate" (Medicina S. A., por L. R. Pinto e Rodrigues Silva), "Poster" (com a Livia Mund), "Lenda" (por Salernitando Masuccio), "Bebida" (os melhores bares do mundo, por E. Greenberg), "Ficção" (Um conto de fadas, por Vladimir Nabokov), "Opiniāo" (Confie no 
A Revista do Homem (Playboy) e a Censura prévia na ditadura militar (I975-I976):

ENTRE A MORAL, OS BONS COSTUMES E O HOMEM CONTEMPORÂNEO

Raphael Diego Greenhalgh e Carlos Henrique Juvêncio da Silva

MDB, por Célio Borja), “Opinião" (Confie no ARENA, por Franco Montoro), “Artigo” (A história da distensão, por C. Castello Branco), "Moda” (Lapidus, Dior, Cerruti e Cardin), "Sátira" (O respeitável Senador, por Hermilio Borba Filho e desenhos de Ziraldo), "Memórias" (Kennedy na intimidade, por Benjamin Bradlee), "Artigo" (A arte de ser patrão, por Jean Paul Getty) e, por fim, “Opinião” (Minha Vez - Pelé) (RIBEIRO, 2016, p. 137).

As propagandas ainda correspondiam a outro ponto de destaque n'A Revista do Homem, promovendo cigarros, joias, instituiçôes financeiras, linhas aéreas, roupas, perfumes, carros, itens de luxo de possível interesse do público alvo da revista, que deveria apreciar o belo não somente nas mulheres, mas também nesses objetos de consumo (GIORDANO, 2012).

A sexualidade dos brasileiros estava em transformação desde a década de 1960, com a revolução sexual mudando as formas com que eles se relacionavam consigo mesmos. $\mathrm{O}$ uso de pílulas anticoncepcionais, a possibilidade do divórcio e o aumento da exploração da nudez, associados à predominante urbanização da população e do aumento dos lares e famílias chefiados por mulheres a partir da década de 1970, exigiam novas representaçóes masculinas (FURQUIM, 2016). Portanto, o playboy era o homem que abria mão da masculinidade pautada na virilidade, na força física e na dominação baseada na violência, de modo que, com esse novo homem que ecoava na revista era necessária a compreensão da mulher liberada, independente financeiramente e que queria ter prazer sexual (FURQUIM, 2016).

\section{Censura na ditadura militar (1964-1985)}

Com a implantação de um governo militar a partir de abril de 1964 a estrutura já existente de censura passou a colaborar com a proibição do regime sob a exteriorização que atentasse contra a moral e os bons costumes e que também fizesse oposição política. As perseguições aumentariam com a implementação do Ato Institucional número 5 (AI-5), em 13 de dezembro de 1968, de modo que "A edição desse ato [AI-5] tornou possível cassar mandatos, suspender direitos políticos e garantias individuais e criou condiçôes para a censura à divulgação da informação, à manifestação de opiniōes e às produções culturais e artísticas" (REIMÃO, 2014, p. 76).

O sistema para censura de jornais e das chamadas diversóes públicas (música, teatro, cinema, rádio, televisão, espetáculos, algumas revistas etc.) foram herdados do Estado Novo, principalmente a partir dos meios usados pelo Departamento de Imprensa e Propaganda (DIP), criado em dezembro de 1939 pelo Decreto-lei n. 1.949 (DOBERSTEIN, 2007). Poucas foram as mudanças dos critérios censórios para diversóes públicas adotados pelo DIP, para o seu sucedâneo, o Serviço de Censura de Diversóes Públicas (SCDP), criado no final de 1945 pelo Decreto-lei 8.426 e regulamentado pelo Decreto 20.493 de 1946 (DOBERSTEIN, 2007). 
A Revista do Homem (Playboy) e a Censura prévia na ditadura militar (I975-I976):

ENTRE A MORAL, OS BONS COSTUMES E O HOMEM CONTEMPORÂNEO

Raphael Diego Greenhalgh e Carlos Henrique Juvêncio da Silva

O SCDP era vinculado ao Departamento Federal de Segurança Pública (DFSP), que em 1967 se tornaria o Departamento de Polícia Federal (DPF), rebatizando entre 1972 e 1973 o SCDP, para Divisão de Censura de Diversóes Públicas (DCDP), deixando o uso do nome Serviço de Censura de Diversóes Públicas (SCDPs) às agências que representavam a DCDP nos estados (DOBERSTEIN, 2007).

A Lei 5.536, de 21 de novembro de 1968, que criou o Conselho Superior de Censura (CSC) compôs o órgão de um representante do Ministério da Justiça, do Ministério das Relaçôes Exteriores, do Ministério das Comunicaçôes, do Conselho Federal de Cultura, do Conselho Federal de Educaçáo, do Instituto Nacional do Cinema, da Fundaçáo Nacional do Bem-Estar do Menor, da Academia Brasileira de Letras, da Associação Brasileira de Imprensa, das Associaçóes Brasileiras dos Autores Teatrais, dos Autores de Filmes, dos Produtores Cinematográficos, dos Artistas e Técnicos em Espetáculos de Diversôes Públicas e dos Autores de Radiodifusão. De modo que esse órgão tinha como competência avaliar recursos das decisões do diretor-geral da DPF relativas à censura de espetáculos e diversões públicas, e elaborar normas e critérios que orientassem o exercício da censura, conforme evidencia Berg (2019).

A partir da lei de criação do CSC, o censor federal passou a ser denominado técnico de censura, e para assumir tal cargo deveria prestar concurso público que exigia a formação superior em Ciências Sociais, Direito, Filosofia, Jornalismo, Pedagogia ou Psicologia (BERG, 2019). A autora ainda diz que o técnico de censura não tinha liberdade para decidir por si só o que poderia ser vetado e que para padronização do processo, esse funcionário recebia treinamento e apostilas da DCDP com orientaçôes do que deveria ou não ser censurado.

O tripé repressivo do regime militar era formado pela produçáo de informaçóes e vigilância/repressão policial, a cargo das Delegacias de Ordem Política Social (Dops), as inteligências militares e o sistema Codi/DOI (Centro de Operaçôes de Defesa Interna - Destacamento de Operaçôes e Informaçôes) e a censura, executada pela DCDP e Gabinete do Ministério da Justiça (NAPOLITANO, 2014).

Entre 1964 e 1968 corresponde ao primeiro de ao menos três momentos de repressáo sobre áreas culturais na ditadura militar, período em que o principal objetivo era "dissolver as conexôes entre a "cultura de esquerda" e as classes populares, estratégia manifestada no fechamento do CPC (Centro Popular de Cultura) e do Iseb (Instituto Superior de Estudos Brasileiros) e dos movimentos de alfabetização de base”, segundo Napolitano (2014, p. 100). $\mathrm{O}$ autor ainda diz que o controle e a perseguição à imprensa eram feitos via Inquéritos Policiais-Militares (IPM) e por processos judiciais, com resultados pífios em termos de puniçóes efetivas, mas que causou bastante insegurança entre os intelectuais.

No segundo momento de repressão, entre 1969 e 1978, para Napolitano (2014, p. 100) o objetivo do regime militar era "reprimir o movimento da cultura como mobilizadora do radicalismo da classe média (principalmente dos estudantes)", a partir, por exemplo, da criação 
A Revista do Homem (Playboy) e a Censura prévia na ditadura militar (I975-I976):

ENTRE A MORAL, OS BONS COSTUMES E O HOMEM CONTEMPORÂNEO

Raphael Diego Greenhalgh e Carlos Henrique Juvêncio da Silva

da nova Lei de Censura, em novembro de 1968, e o Decreto-lei 1.077, de janeiro de 1970, que instaurou a censura prévia sobre materiais impressos. Enquanto, no terceiro momento, entre 1979 a 1985, o objetivo central era "controlar o processo de desagregação da ordem política e moral vigentes, estabelecendo limites de conteúdo e linguagem" (NAPOLITANO, 2014, p. 101), com ênfase no controle censório na moral e nos bons costumes.

Na visão de Kushnir (2012, p. 115) o Decreto-lei 1.077 “[...] legalizou a existência da censura prévia". Pensamento este que contrapóe o entendimento de outros historiadores, como por exemplo Smith (2000), para quem o decreto não era um instrumento de censura prévia, pois conforme os informes do governo, a censura sequer existia. De fato, o Decreto-lei 1.077 proibia expressamente "[...] as publicaçôes e exteriorizaçôes contrárias à moral e aos bons costumes" e trazia a prerrogativa do Ministro da Justiça fazer censura prévia "quando julgar necessário".

Art. $1^{\circ}$ Não serão toleradas as publicações e exteriorizações contrárias à moral e aos bons costumes quaisquer que sejam os meios de comunicação.

Art. 2o Caberá ao Ministro da Justiça, através do Departamento de Polícia Federal verificar, quando julgar necessário, antes da divulgação de livros e periódicos, a existência de matéria infringente da proibição enunciada no artigo anterior.

Parágrafo único. O Ministro da Justiça fixará, por meio de portaria, o modo e a forma de verificação prevista neste artigo.

Art. $3^{\circ}$ Verificada a existência de matéria ofensiva à moral e aos bons costumes, o Ministro da Justiça proibirá a divulgação da publicação e determinará a busca e apreensão de todos os seus exemplares (BRASIL, 1970).

A Portaria 11-B, de 6 de fevereiro de 1970, regularia o Decreto-lei 1.077 ao determinar que todas as publicaçóes deveriam ser enviadas para o Ministério da Justiça para julgamento prévio, conforme atesta Reimão (2014). A autora ainda relata que após incisiva reação contra a censura prévia, de editores, escritores, intelectuais e associaçôes da sociedade civil, o governo recuou e publicou a Instrução 1-70, de 24 de fevereiro de 1970. Tal dispositivo isentava de verificação prévia as publicaçôes de caráter estritamente filosófico, científico, técnico e didático, bem como as que não versassem sobre temas referentes ao sexo, moralidade pública e bons costumes.

Segundo Kushnir (2012) o decreto secreto 165-B/71 vindo do Ministro da Justiça também regulava a censura ao trazer dez pontos proibitivos sobre o que não devia ser tratado pelos meios de comunicação:

a. campanha pela revogação dos Atos Institucionais, notadamente o Ato Institucional no 5 , de 13 de dezembro de 1968; 
A Revista do Homem (Playboy) e a Censura prévia na ditadura militar (I975-I976):

ENTRE A MORAL, OS BONS COSTUMES E O HOMEM CONTEMPORÂNEO

Raphael Diego Greenhalgh e Carlos Henrique Juvêncio da Silva

b. manifestaçóes de inconformidade com a censura em diversóes e espetáculos públicos, livros, periódicos e em exteriorizações pelo rádio e televisão, realizada com base no Decreto-lei no 1.077/70, de 26 de janeiro de 1970;

c. apreciaçóes que envolvam contestaçóes ao regime vigente;

d. divulgação de notícias sensacionalistas que possam prejudicar a imagem do Brasil no exterior;

e. divulgação de notícias com o objetivo de agitar os meios sindicais e estudantis;

f. divulgação de notícias a respeito da existência de censura, salvo a de diversóes públicas, bem como de prisões de natureza política;

g. divulgação de notícias tendenciosas a respeito de assaltos a estabelecimentos de crédito, nomeadamente a descrição minuciosa de quaisquer crimes ou atos antissociais;

h. divulgação de quaisquer notícias que venham a criar tensôes de natureza religiosa;

i. divulgação de notícias que venham a colocar em perigo a política econômica do Governo;

j. divulgação alarmista de movimentos subversivos em países estrangeiros, bem como a divulgação de qualquer notícia que venha a indispor o Brasil com nações amigas (KUSHNIR, 2012, p. 119-120).

Como mostram os tópicos "b" e "f", a exteriorização contrária à censura prévia também era proibida. Reimão (2011) evidencia tal fato ao expor texto taxativo da Polícia Federal (de 4 de junho de 1973) sobre a impossibilidade de questionamento ao sistema censório:

De ordem superior, fica terminantemente proibida a publicação de críticas ao sistema de censura, seu fundamento e sua legitimidade, bem como qualquer notícia, crítica, referência escrita, falada e televisada, direta ou indiretamente formulada contra órgão de censura, censores e legislação censória (REIMÃO, 2011, p. 11).

A censura exercida pela DCDP era bastante conhecida do público, liberada sua divulgação pelo tópico " $F$ ", mas proibido o descontentamento com ela pelo tópico "B" do decreto secreto $165-B / 71$. A censura proibida de ser comentada pelo tópico "F" é principalmente aquela exercida pelo Serviço de Informação do Gabinete (SIGAB) do Ministério da Justiça, o qual em primeiro momento enviava bilhetes e posteriormente passou a ligar para as redaçóes dos jornais dizendo o que poderia ou não ser publicado. De modo que havia uma censura oficial exercida pela DCDP e outra clandestina com o SIGAB, como mostra Doberstein (2007). A Revista do Homem estava sob a censura prévia da DCDP, mas, em algumas ocasiōes, foram solicitadas avaliações ao SIGAB referentes a possíveis censuras políticas no conteúdo de suas matérias, como será visto adiante. 
A Revista do Homem (Playboy) e a Censura prévia na ditadura militar (I975-I976):

ENTRE A MORAL, OS BONS COSTUMES E O HOMEM CONTEMPORÂNEO

Raphael Diego Greenhalgh e Carlos Henrique Juvêncio da Silva

\section{Censura prévia em A Revista do Homem}

A Revista do Homem surge em um momento político-histórico em que havia uma preocupação maior dos órgãos censores sobre publicaçóes eróticas, pornográficas e/ou com conteúdo sobre sexualidade, pois atentavam contra a moral e os costumes conservadores. Nesse sentido, também pode ser vista uma associação ideológica entre moral e política, com o imaginário de determinados setores da sociedade relacionando os comunistas à imoralidade. De modo que grande número de organizaçóes religiosas, certos grupos de militares e mesmo algumas pessoas comuns viam no erotismo e na pornografia uma estratégia de corrupçáo da juventude e da família tradicional cristá, conforme mostra Marcelino (2006).

Em entrevista a Manoel Risério, Roberto Civita (editor da revista) disse que, ao tentar autorização para lançamento da Playboy no Brasil, recebeu telefonema de um coronel dizendo que o Ministro da Justiça, Armando Falcão, havia dito que nada com este título poderia ser lançado no país, independentemente do seu conteúdo. Dessa forma, trocaram o nome para $A$ Revista do Homem, visto que só o título inicial estava proibido. Civita também disse que certa vez um general o chamou e lhe disse que estava preocupado com um navio vindo da Dinamarca cheio de revistas pornográficas para serem distribuídas no Brasil e que isso era um plano dos comunistas soviéticos para corromper as instituiçôes e os alicerces da família brasileira, já que de alguma forma esse general estava fazendo um paralelo à Playboy (por ele considerada pornográfica) e por isso alertava-o a respeito ${ }^{1}$.

Diante desse contexto de repressão ao erotismo, a Homem conseguiu se firmar devido ao fato de a estratégia empresarial da Editora Abril estar alinhada com os objetivos geopolíticos da ditadura militar, segundo Giordano (2012). Pois, de acordo com a autora, "A integração nacional através da ampliação do mercado interno tanto como a integraçáo do Brasil com o sistema internacional (ao lado dos países mais desenvolvidos, daí a consignação 'Brasil, potência') eram objetivos comuns do Estado e da editora" (GIORDANO, 2012, p. 153).

Segundo Ribeiro (2016) os censores da Homem seguiam à risca um manual de conduta, em que seios e nádegas só eram liberados um por página e de perfil, vetando categoricamente bicos, mamilos e pelos pubianos. Proibiçôes essas que seriam explicitadas em circular de Rogério Nunes (chefe da DCDP) às revistas para público masculino. Enviada no início de 1977, ela dizia que não eram permitidas fotografias que fixassem:

a) atos sexuais; b) nádegas completamente nuas; c) seios totalmente à mostra; d) região púbica descoberta e desprovida de sunga, tanga, biquíni ou qualquer peça do vestuário; e) modelos em poses lascivas; f) relacionamentos homossexuais; g) indumentárias transparentes, permitindo visualizar partes íntimas do corpo (SIMÔES, 1999, p. 194-195).

\footnotetext{
${ }^{1}$ Parte da entrevista está presente em Ribeiro (2016, p. 142).
} 
A Revista do Homem (Playboy) e a Censura prévia na ditadura militar (I975-I976): ENTRE A MORAL, OS BONS COSTUMES E O HOMEM CONTEMPORÂNEO

Raphael Diego Greenhalgh e Carlos Henrique Juvêncio da Silva

Segundo dados levantados por Ribeiro (2016, p. 151), A Revista do Homem teve 13 ediçôes censuradas (desde o número 3) e mais uma edição de Humor, em que 606 linhas foram vetadas, 30 fotos tiveram cortes, 35 fotos foram vetadas, 59 fotos foram retocadas, nove cartuns foram vetados, três cartuns foram retocados, além do corte de um trecho do artigo do senador Teotônio Vilela ("Um modelo para o Brasil", Homem 7, no qual propunha a revogação do AI-5) (RIBEIRO, 2016, p. 151). Contudo, a partir dos pareceres presentes no Fundo da DCDP no AN, foram censurados 17 números da revista, conforme os dados a seguir.

\section{Pareceres da DCDP: a moral, os bons costumes, o erótico e o pornográfico}

O presente trabalho corresponde a uma pesquisa descritiva e histórica, a partir de uma análise documental, com abordagem quali-quantitativa. Para isso, foram estudados os 122 pareceres da censura prévia para A Revista do Homem custodiados pelo Arquivo Nacional (Coordenação Regional em Brasília - COREG), no fundo da DCDP, na seção Censura Prévia e na série Publicaçôes ${ }^{2}$. Os pareceres foram redigidos entre 3 de setembro de 1975 e 3 de janeiro de 1977, correspondentes às observaçôes dos censores para os números 3 a 19 da revista (17 números ao todo). Apesar dos originais da revista não constarem juntos aos pareceres, o que dificulta saber o que exatamente foi cortado ou sugerido corte, a análise desses documentos permite verificar nuances do processo censório de modo a entender melhor o que era proibido e perseguido nesse período do governo militar, além da identificação de detalhes da organização administrativa da censura.

As tratativas a respeito do número 1 d'A Revista do Homem não constam no fundo da DCDP, mas no do Ministério da Justiça. Sua análise é importante, pois trará implicação nos demais pareceres aqui estudados. No dia 29 de julho de $1975^{3}$, o diretor da DCDP encaminha o referido número da revista para apreciaçáo do Ministro da Justiça. Em parecer da Assessoria Especial do Gabinete do Ministério da Justiça, de 6 de agosto de 1975, o delegado da Polícia Federal, Jesuan de Paula Xavier diz que houve exagero na retratação da mulher, pois do modo como foram feitas as fotos e charges "mais se prestariam para compor revistas eróticas, do gênero Playboy". As fotos das modelos que aparecem entre as páginas 42 a 47 e 68 a 74 revelam a nudez das mulheres deixando os seios à mostra. $\mathrm{O}$ parecerista diz que, em conversa com o diretor da DCDP, este afirmou que a verificação prévia tinha sido feita no "boneco" xerografado e que por isso não davam ideia nítida das ilustraçóes, de modo que esse fato não se repetiria.

\footnotetext{
2 BRASÍlIA (DF). Arquivo Nacional. Requerimentos para liberação da Revista do Homem. 1975-1976. Códigos de arquivamento: BR DFANBSB NS.CPR.PUB.198; BR DFANBSB NS.CPR.PUB.319.

${ }^{3}$ RIO DE JANEIRO (RJ). Arquivo Nacional. Processo DICOM no 61.805. 1975-1976. Códigos de arquivamento: BR RJANRIO TT.0. MCP, PRO.436
} 
A Revista do Homem (Playboy) e a Censura prévia na ditadura militar (I975-I976): ENTRE A MORAL, OS BONS COSTUMES E O HOMEM CONTEMPORÂNEO

Raphael Diego Greenhalgh e Carlos Henrique Juvêncio da Silva

As questóes políticas também foram averiguadas no parecer a respeito do número 1 de Homem. O delegado Jesuan aponta, por exemplo, que no artigo do jornalista Carlos Castello Branco foram revolvidos "assuntos políticos já vencidos e superados e que seria de toda conveniência não fossem mais ventilados, sob tais perspectivas, que poderão abrir dúvidas quanto à verdadeira definição filosófica do atual Governo". Nesse caso, o jornalista questionava a lentidão e as medidas adotadas pelo presidente em relaçáo aos desafios apresentados para a distensão e abertura do regime militar. Por isso, o parecerista diz que a DCDP se encarregou apenas da avaliação prévia, mas não tomou e nem sugeriu providências, como também era sua prerrogativa. Tais questóes envolvendo as matérias políticas e o erotismo presentes na revista seriam reavaliadas nos pareceres posteriores, conforme é possível observar a seguir. Sobre a política, os censores deveriam pedir auxílio aos seus supervisores para avaliação precisa e a nudez passaria a ser suavizada.

Nos pareceres presentes na DCDP é possível observar que as matérias e seçôes da revista eram repassadas a diversos censores, ou seja, não era um mesmo censor que avaliava todas as partes de um mesmo número da revista. Foram identificados ao todo 36 censores atuando na análise dos 17 números da Homem, o que dá uma média de mais de dois censores por número. Contudo, apenas cinco números tiveram três censores ou menos, os números 3 , 12, 15, 18 e 19. Os números que tiveram mais censores atuando foram os números 6 (nove censores), 8 (oito censores), 11, 13, 14, 16 e 17 (todos com seis censores). Esses números demonstram como era grande e organizado o aparato censor nesse período.

A dispersão das diversas seçôes da revista a múltiplos censores fazia com que os muitos pareceres para um único número fossem emitidos em várias datas diferentes, o que provavelmente aumentava o tempo necessário para essa análise. Em média eram necessários aproximadamente 33 dias para a análise de um mesmo número da revista, com essa quantidade de dias correspondendo ao intervalo da emissão do primeiro parecer até o último para um mesmo número ${ }^{4}$. $\mathrm{Na}$ análise das seçôes do número 13 da revista, foram necessários 43 dias do primeiro ao último parecer, enquanto no número 16 foram 56 dias e no número 15 foram 72 dias. A demora na análise dos números demandava organização e antecipação da revista caso quisesse se manter dentro da periodicidade (mensal), visto que normalmente se levava mais de um mês para avaliação dos números e outros levavam quase três meses para serem analisados.

Além da análise dos censores era comum que os pareceres ainda fossem revisados. Dos pareceres analisados, quase $1 / 3$ foi revisado por superiores, num total de $39(31,96 \%)$ pareceres revisados. Foram identificados também cinco revisores diferentes. Os censores frequentemente encaminhavam para avaliaçáo superior caso não se sentissem aptos à análise do conteúdo, como por exemplo, no parecer 381, referente aos números 13 e 14 da revista, em que a censora diz que náo identificou itens que deveriam ser retirados ou retificados no

\footnotetext{
${ }^{4}$ Não foi possível identificar quanto tempo se levava da chegada dos originais até a emissão do primeiro parecer, pois não consta tal informação nos documentos analisados.
} 
A Revista do Homem (Playboy) e a Censura prévia na ditadura militar (I975-I976): ENTRE A MORAL, OS BONS COSTUMES E O HOMEM CONTEMPORÂNEO

Raphael Diego Greenhalgh e Carlos Henrique Juvêncio da Silva

texto, mas que as ilustraçóes que "fogem à nossa alçada" eram encaminhadas para "consideração da autoridade superior", acrescentando ainda que "assim é determinado". Essa revisão se dava devido à pressão exercida sobre o técnico de censura, de modo que caso ele liberasse algo que posteriormente fosse identificado como proibido, poderia vir a sofrer sançóes, conforme aponta Vieira (2010).

A última palavra do que deveria ser retirado ou retificado era do supervisor, que usava de sua autoridade para desconsiderar aquilo que havia sido indicado como impróprio pelo censor. Dos 39 pareceres em que houve algum tipo de revisão pelos supervisores, em 16 houve impugnação parcial e, em cinco pareceres, impugnação total dos cortes que o censor havia proposto. Ou seja, em mais da metade $(53,84 \%)$ dos pareceres que os supervisores revisaram eles decidiram intervir nas decisóes tomadas pelos censores.

Caso os supervisores ainda tivessem dúvidas em relação à proibição ou liberação de determinada matéria, poderiam recorrer a uma terceira opinião, a do Serviço de Informação do Gabinete (SIGAB). Exemplo disso é o parecer sobre matéria do senador Marcos Freire que criticava o AI-5, o qual o censor encaminhou ao seu supervisor e posteriormente o Diretor da DCDP enviou ao SIGAB. A matéria foi liberada na íntegra pelo SIGAB e teve a decisão acatada pelo Diretor da $\mathrm{DCDP}^{5}$. Ainda houve situação similar em análise de matéria do economista Paul Samuelson, vencedor do prêmio Nobel de Economia em 1970, em cujo artigo ele fazia um confronto entre capitalismo e socialismo, levando o censor a desconfiar que o texto poderia ser nocivo ideologicamente, recomendando o envio da matéria para apreciação do SIGAB, o que foi feito pelo Diretor da DCDP6.

N'A Revista do Homem a censura foi muito presente, pois foram indicados cortes em todos os 17 números presentes nos pareceres da DCDP. Cerca de 1/3 (41 pareceres, 33,6\%) dos 122 pareceres apresentam algum tipo de corte que os editores da revista deveriam fazer. Todas as estruturas da revista foram analisadas, como a capa, o índice, fotografias, desenhos, piadas, além das matérias e artigos. No geral os censores propuseram cortes de cunho moral, com esse tipo de censura em 25 pareceres (o que corresponde a aproximadamente 61\% dos pareceres com indicação de cortes). Contudo, apesar de repassarem aos seus superiores quando desconfiavam que o conteúdo poderia exigir a censura política, para alguns censores, a censura política não estava totalmente descartada. Em dois dos 25 pareceres com cortes de fundo moral, também há cortes de teor político, assim como em outros dois pareceres os cortes sugeridos são apenas de cunho político?

\footnotetext{
${ }_{5}^{5}$ BRASÍlIA (DF). Arquivo Nacional. Parecer 623, para A Revista do Homem n. 19: matéria do senador Marcos Freire. 17 de dezembro de 1976.

${ }^{6}$ BRASÍlLA (DF). Arquivo Nacional. Parecer 413, para A Revista do Homem [sem número]: matéria "O grande debate. 31 de agosto de 1976.

${ }^{7}$ Como os originais da revista não estavam acompanhando os pareceres, em 14 deles não foi possível identificar o tipo de censura sofrida, se moral ou política.
} 
A Revista do Homem (Playboy) e a Censura prévia na ditadura militar (I975-I976): ENTRE A MORAL, OS BONS COSTUMES E O HOMEM CONTEMPORÂNEO

Raphael Diego Greenhalgh e Carlos Henrique Juvêncio da Silva

As censuras políticas se deram principalmente em relação a matérias ou posicionamentos considerados contrários ao regime militar ou depreciativos à figura do militar. Em parecer referente à Revista do Homem número $7^{8}$, o censor ordena cortes em três páginas de "Modelo político", matéria na qual o Senador Teotônio Vilela "analisa politicamente o Brasil, depois de 1964, enfatizando a necessidade da criação de um modelo político definido", em que foram expostas "algumas idéias [sic] contrárias ao AI-5". Já no parecer em relação à Homem número $10^{9}$, os dois censores que assinam o parecer dizem que o artigo "A nossa vida é o céu", de autoria de Ray Bradbury, "contém insinuaçôes que podem levar o leitor a falsas ilaçôes" e por isso sugerem a retirada do trecho "está chacoalhando nos bolsos dos nossos militares". Também é sugerido o corte de um quadro na matéria "Papagaio", da Homem número $13^{10}$, pois a censora considerou a piada presente nesse local como depreciativa aos militares.

A maioria dos cortes sugeridos pelos censores foram por atentar "contra a moral e os bons costumes", por se tratarem de "palavrôes" ou "expressôes deseducadas", "inconveniente", "audaciosa", "de baixo calão", "vulgar”, "grosseira”, "picante", "insolente”, com "linguagem não permissiva", "chula", por ter "liberdade excessiva" ou por ser "pseudo-ciência” [sic]. Exemplos do tipo de palavras que os censores enquadravam nas categorias mencionadas anteriormente podem ser vistas nas solicitaçóes de retirada das palavras "porra"11, "puto", "putinha"12 ou "puta"13 (com exceçấo da primeira palavra, os cortes das demais foram revogados pelos revisores). Também foram cortados pelos censores as expressôes "e porque sempre dei para quem eu quis" 14 , "parece que tem o pau de ferro", "orgulhosos e superexcitado... até... pensou", "manda brasa"15 e "esse filho da puta"16.

$\mathrm{Na}$ análise de exemplares impressos de A Revista do Homem é possível ver as adaptaçóes que eram feitas nos cortes da censura, por exemplo, a expressão "e porque sempre dei para quem eu quis" foi alterada para "e porque sempre fiz aquilo que eu quis". Enquanto na expressão "esse filho da puta" o recurso usado para suprimir a expressão foi outro, com o uso de reticências nos locais considerados inadequados, ficando: "Gostaria mesmo que você

\footnotetext{
${ }^{8}$ BRASÍlLIA (DF). Arquivo Nacional. Parecer 4, para A Revista do Homem n. 7.5 de janeiro de 1976.

${ }^{9}$ BRASÍlIA (DF). Arquivo Nacional. Parecer 184, para A Revista do Homem n. 10.22 de março de 1976.

${ }^{10}$ BRASÍlLIA (DF). Arquivo Nacional. Parecer 339, para A Revista do Homem n. 13. 24 de junho de 1976.

${ }^{11}$ BRASÍlLIA (DF). Arquivo Nacional. Parecer 11, para A Revista do Homem n. 7: entrevista com o jogador de futebol Didi. 7 de janeiro de 1976.

${ }^{12}$ BRASÍLIA (DF). Arquivo Nacional. Parecer 9.187, para A Revista do Homem n. 5: conto "Flores para Ritinha", de Dalton Trevisan. 3 de novembro de 1975. (o conto na verdade saiu na Homem, n. 6).

${ }^{13}$ BRASÍLIA (DF). Arquivo Nacional. Parecer 283, para A Revista do Homem [sem número]: artigo "Os amores de um professor de inglês". 26 de maio de 1976.

${ }^{14}$ BRASÍLIA (DF). Arquivo Nacional. Parecer 41, para A Revista do Homem n. 8: reportagem "Itala Nandi". 20 de janeiro de 1976.

${ }^{15}$ BRASÍlIA (DF). Arquivo Nacional. Parecer 184, para A Revista do Homem n. 10: as duas primeiras expressôes no artigo "A mulher que apanhou o super-homem" e a outra no artigo "O rugido do Jaguar". 22 de março de 1976.

${ }^{16}$ BRASÍLIA (DF). Arquivo Nacional. Parecer 354, para A Revista do Homem n. 13: depoimento de Sara Jane Moore. 2 de julho de 1976.
} 
A Revista do Homem (Playboy) e a Censura prévia na ditadura militar (I975-I976):

ENTRE A MORAL, OS BONS COSTUMES E O HOMEM CONTEMPORÂNEO

Raphael Diego Greenhalgh e Carlos Henrique Juvêncio da Silva

tivesse matado esse $\mathrm{f} . .$. da p...!"17. Reticências também usadas como recurso de censura nos trechos do conto de Antônio Calado, na página 34 de Homem número 16, ficando: "Hoje passei meu teste de atriz na Embaixada e quase passo o de p... na garagem quando um tal de Claudionor sem aviso prévio me levantou a saia pelo lado e enfiou pelas calcinhas e x... um pai-de-todos tão formado em siriricologia que....”.

Uma pergunta de um leitor encaminhada à revista e consequentemente a resposta do editor também foram censuradas por atentar contra a moral e os bons costumes, pois o leitor indaga "se o tamanho do pênis influi no ato sexual" de modo que isso se colocaria contra "o que dispóe o art. $1^{\circ}$ do Decreto-lei 1077/70"18, dispositivo legal que instituiu a censura prévia em livros e periódicos. Outra censura que merece destaque é a que é sugerida e parcialmente acatada em relação ao artigo "10 mitos sexuais" ${ }^{\text {. }}$. Apesar de longa, vale a citação na íntegra da análise do censor, principalmente pelo julgamento deste sobre a falta de qualidade científica na matéria, ou mesmo sua evocação de termos científicos e linguísticos como "análise do discurso", "semiológico" e "formas de linguagem" no intuito de provar que o texto foi feito para convencer e provocar a mudança de comportamento sexual no leitor.

Quanto ao segundo artigo, intitulado "10 mitos sexuais", é redigido com rótulo de autoridade, em termos de definiçấo em torno de delicados temas do ponto de vista sexual, observando-se duas estruturas de linguagem:

a. Uma pseudo-científica [sic], de início confundindo fato social com mito (este tem conotaçóes de conceito diversas do tratamento emprestado ao artigo). Esta confusão de conceitos tende a gerar novas aberturas da consciência individual e coletiva numa era de crescente desmistificação e revisão de atitudes, principalmente quando novas contribuiçôes são manifestadas com véus de autoridade última em determinado assunto;

b. outra tem características indutivo-persuasivas. A análise do discurso, do ponto de vista semiológico, permite verificar formas de linguagem cuja função é a de convencer o leitor à adoção de novos comportamentos, a título de uma atitude "conscientemente" desmistificadora, que vão desde posturas sexuais até a sublimação do instinto. Permite, portanto, deduzir-se que o que era negado ontem é permitido hoje, pela aparente posse final da verdade.

Evidentemente, ao longo deste artigo há conceitos clássicos e insofismáveis, de assentimento global. Por outro lado, trata-se de matéria mais afeta à experiência norte-americana. Mas em contrapartida, prevalece o aspecto final, conclusivo sobre o assunto, sem características de premissas postas à discussáo, numa aparente filtragem do acervo das indagaçóes e pesquisas sobre o sexo.

\footnotetext{
${ }^{17}$ MOORE, Jane. Depoimento. A Revista do Homem, n. 13, 1976, p. 139.

${ }^{18}$ Art. $1^{\circ}$ - Não serão toleradas as publicaçôes e exteriorizaçôes contrárias à moral e aos bons costumes quaisquer que sejam os meios de comunicação. (BRASIL. Decreto-lei 1.077, de janeiro de 1970).

${ }^{19}$ BRASÍLIA (DF). Arquivo Nacional. Parecer [sem número], para A Revista do Homem [sem número]: artigo "10 mitos sexuais". 12 de novembro de 1975.
} 
A Revista do Homem (Playboy) e a Censura prévia na ditadura militar (I975-I976):

ENTRE A MORAL, OS BONS COSTUMES E O HOMEM CONTEMPORÂNEO

Raphael Diego Greenhalgh e Carlos Henrique Juvêncio da Silva

Nestas condiçôes, pelas características com que é apresentado o texto e pelos objetivos que este procura alcançar e, ainda, pela influência que exercerá sobre os leitores carentes de espírito crítico hábil, em especial o adolescente, sou pela proibição parcial deste último artigo, ou melhor pelo desaconselhamento dos itens abaixo discriminados, em respeito à vulnerabilidade dos jovens; peculiar aos que transitam na faixa 14-16 e 16-18 anos:
a) A posição mais satisfatória é com o homem por cima;
b) as prostitutas, ou são frígidas ou homossexuais;
c) o sexo anal é uma perversão e representa perigo;
d) é bom sublimar o impulso sexual por longos períodos. ${ }^{20}$

Dos quatro itens que o censor sugeriu a retirada, o corte mantido pelo supervisor foi apenas o do item "c". Ou seja, o que a publicação chamou de mito a respeito dos hábitos sexuais, como por exemplo que "o sexo anal é uma perversão e representa perigo", não foi considerado como tal pela censura. Portanto, ao tratar como contraditória a propositura da revista, a censura passa a ter um efeito afirmativo, em que consequentemente para os censores e para o governo que eles representam, sim, "o sexo anal é uma perversão e representa perigo" e o incentivo de sua prática seria subversivo, principalmente para os jovens leitores.

Os desenhos, charges e fotografias também eram analisados, de modo que alguns foram enquadrados pelos censores como imorais. Por exemplo, em um dos pareceres o censor veta duas charges, pois elas "sugerem atitudes indecorosas". A primeira apresentava "um marido surpreendendo o seu cão (em estado de estafa) ao lado da esposa" e a segunda mostrava "uma mulher chupando um dos dedos do pé de um homem, dando a entender que aquela estaria acariciando o pênis deste" 21 . Mesmo em uma revista erótica como A Revista do Homem a nudez sempre era objeto de maiores preocupaçóes dos censores, como, por exemplo, o caso em que uma censora manda para apreciação dos superiores quadros onde se encontram nus em duas seções da Homem número $13 .^{22}$

$\mathrm{Na} A$ Revista do Homem número 4, a censora não libera 17 fotos, pois correspondem a "fotos ousadas, detalhando ângulos atentatórios à moral" com "farto material de mulheres nuas, com destaque para nádegas, seios, e pelos pubianos", além de "poses eróticas”. Mesmo as fotografias publicitárias eram averiguadas se apresentavam nudez desproporcional, como por exemplo, no caso em que o censor não libera a imagem, pois a "mulher se acha em posição de nudez imoral", recomendando inclusive verificar "a possibilidade de uma montagem

\footnotetext{
${ }^{20}$ BRASÍLIA (DF). Arquivo Nacional. Parecer [sem número], para A Revista do Homem [sem número]: artigo "10 mitos sexuais". 12 de novembro de 1975.

${ }^{21}$ BRASÍLIA (DF). Arquivo Nacional. Parecer [sem número], para A Revista do Homem n. 7: seção Humor. 22 de dezembro de 1975.

${ }^{22}$ BRASÍlIA (DF). Arquivo Nacional. Parecer 339, para A Revista do Homem n. 13: piadas das seçóes "Folkes" e "Humor". 24 de junho de 1976.
} 
A Revista do Homem (Playboy) e a Censura prévia na ditadura militar (I975-I976): ENTRE A MORAL, OS BONS COSTUMES E O HOMEM CONTEMPORÂNEO

Raphael Diego Greenhalgh e Carlos Henrique Juvêncio da Silva

para suprimir o mamilo e escurecer a parte que mostra as nádegas"23, que caso não fosse possível, deveria enviar outra foto para apreciação. Nesse sentido, alguns subterfúgios foram usados pela Homem para enquadrar o nu nas regras da censura, como por exemplo, o uso de uma estrela para a cobertura do mamilo de uma modelo, colocada intencionalmente para tampá-lo. ${ }^{24}$ Embaçar os mamilos também era outro recurso que visava "suavizar" a nudez, com o intuito de manter as fotografias dentro dos padróes aceitáveis pela censura. ${ }^{25}$

A análise dos pareceres demonstra certa falta de unidade nas censuras, visto que determinadas coisas eram proibidas por alguns censores e outras similares eram liberadas por outros avaliadores. Por exemplo, duas matérias que questionam o AI-5, ambas escritas por senadores, recebem tratamento diferenciado. A primeira que sairia na Homem número 7 tem indicados cortes nas partes que atentam contra tal dispositivo legal criado no governo militar em 1968. Já a segunda, que sairia na Homem número $19^{26}$ é liberada na íntegra, mesmo com o censor alertando os supervisores que o senador Marcus Freire apontava diversas saídas para a revogação do referido Ato Institucional, pois as prerrogativas que confere o Executivo tornavam esse Ato "a negação da democracia pregada pela revolução".

No âmbito moral também existiram incongruências, como já demonstrados nos cortes de algumas palavras e na liberação de outras similares, como a palavra "porra" proibida e "puto" e "putinha” liberadas. Além disso, apesar de aquilo que atente contra a moral e os bons costumes deva ser vetado, para alguns censores também há o entendimento de que devido ao escopo da revista ser o erotismo, deve-se ter uma maior tolerância com o que é considerado picante ou libidinoso. De modo que não há parâmetro que possa ser estabelecido para determinar o limite dessa tolerância. Por exemplo, em parecer o censor diz que apesar de a matéria "apresentar passagens levemente eróticas", permanece "dentro dos limites permitidos para o veículo". ${ }^{27}$ Também houve o caso em que um censor liberou uma matéria que "apresenta algumas gravuras audaciosas mas toleráveis em função do contexto e a linha geral da revista" ${ }^{28}$

Para emissão de seus pareceres, por vezes, os censores olhavam para além da questão moral ou política, pois em alguns casos a qualidade de redação da matéria ou o nível de consagração do autor influíam em sua decisão. Ao julgar um trecho do livro Memórias, de Pedro Nava, que sairia na Homem número 7, por exemplo, o censor escreve em parecer que

\footnotetext{
${ }^{23}$ BRASÍLIA (DF). Arquivo Nacional. Parecer 574, para A Revista do Homem [sem número]: fotografia publicitária. 24 de novembro de 1976.

${ }^{24}$ A Revista do Homem, n. 8, 1976, p. 38.

${ }^{25}$ Exemplos dessa prática podem ser vistos em A Revista do Homem, n. 13, 1976, p. 47, 72 e 103.

${ }^{26}$ BRASÍlIA (DF). Arquivo Nacional. Parecer 623, para A Revista do Homem n. 19: matéria do senador Marcos Freire. 17 de dezembro de 1976.

${ }^{27}$ BRASÍlIA (DF). Arquivo Nacional. Parecer 498, para A Revista do Homem n. 16-A e 17: matéria "Zélio. 14 de outubro de 1976.

${ }^{28}$ BRASÍLIA (DF). Arquivo Nacional. Parecer 234, para A Revista do Homem n. 11: matéria "Humor". 22 de abril de 1976.
} 
A Revista do Homem (Playboy) e a Censura prévia na ditadura militar (I975-I976): ENTRE A MORAL, OS BONS COSTUMES E O HOMEM CONTEMPORÂNEO

Raphael Diego Greenhalgh e Carlos Henrique Juvêncio da Silva

ao descrever o amor de um primo por uma das empregadas, apesar de o autor empregar descriçôes, ele usa "simbolismos e imagens literárias sem qualquer intenção [...] de estimular o desejo sexual no leitor", pois o texto era "muito bem apresentado, [...] é literatura, sem qualquer segunda intenção". ${ }^{29}$ Ao analisar as matérias "Abertura", "Comida", "Leitura", "Teatro", "Esporte", "Noite", "Calendário" e "Cinema”, outro censor escreve que "ao exame constata-se que todas as matérias estão redigidas de forma jornalística sem implicaçôes que justifiquem restriçốes por parte da DCDP". ${ }^{30}$

Em um dos pareceres para matérias da Homem número 4, o primeiro item argumentativo para liberação do conteúdo é devido aos "textos inteligentes, visando, tão-somente [sic], entretenimento e informação". ${ }^{31}$ Em outro parecer o censor indica a liberação sem restriçôes, pois "as matérias examinadas referem-se a quadros humorísticos de autores consagrados nos meios jornalísticos". 32

Em dois dos quatro pareceres citados no parágrafo anterior ainda é possível verificar outra incongruência na análise dos censores, pois nesses pareceres além da qualidade do conteúdo, também é motivo para liberação do texto o fato deste estar alinhado com o público da revista, ou seja, o adulto. Enquanto, por vezes, o fato de a revista poder chegar às máos de adolescentes também é levado em consideração no sentido de proibir o conteúdo, como é o caso da censura à matéria "10 mitos sexuais", já citada acima. Também é o caso da censura a artigos que abordavam o aborto e o sexo livre, temas merecedores de maior rigor da Censura Federal, pois estariam em "periódicos lançados em venda pública, e, que são lidos por todo tipo de leitor (e não há como controlar)", assim como "o receptor, isto é, o leitor, juvenil e adolescente ao ter acesso a tal artigo, de certo será por ele afetado. Por via de consequência, estariam em posição de perigo, dois valores morais e sociais básicos da célula familiar - o direito à vida e a fidelidade conjugal".33

\section{Considerações finais}

A análise dos pareceres dos técnicos de censura da DCDP permitiu identificar nuances do processo censório durante o período estudado. A partir deste levantamento foi possível ver como o governo lidou com a situação paradoxal de permitir uma revista de cunho eró-

\footnotetext{
${ }^{29}$ BRASÍlIA (DF). Arquivo Nacional. Parecer 10.181, para A Revista do Homem n. 7: trecho de Memórias, de Pedro Nava. 11 de dezembro de 1975.

${ }^{30}$ BRASÍLIA (DF). Arquivo Nacional. Parecer 397, para A Revista do Homem n. 14: matérias "Abertura", "Comida", "Leitura", “Teatro", "Esporte”, "Noite", "Calendário" e "Cinema”. 10 de agosto de 1976.

${ }^{31}$ BRASÍlIA (DF). Arquivo Nacional. Parecer 8.370, para A Revista do Homem n. 4.6 de outubro de 1975.

${ }^{32}$ BRASÍLIA (DF). Arquivo Nacional. Parecer [sem número], para A Revista do Homem [sem número]: matérias "Homem para homem" e "Nossos clássicos". 8 de junho de 1976.

${ }^{33}$ BRASÍLIA (DF). Arquivo Nacional. Parecer 254, para A Revista do Homem [sem número]: quadros de Buchwald, Carlos Eduardo, Woody Allen, Xadrez e Verissimo; artigos “Barão de Itararé”, “Groucho” e “Teste”. 1976.
} 
A Revista do Homem (Playboy) e a Censura prévia na ditadura militar (I975-I976):

ENTRE A MORAL, OS BONS COSTUMES E O HOMEM CONTEMPORÂNEO

Raphael Diego Greenhalgh e Carlos Henrique Juvêncio da Silva

tico, em um momento que se tinha como uma das suas metas a manutenção e a ampliação dos valores conservadores. Para isso a nudez era tolerada até certo limite, mesmo em uma revista que tinha como foco o público masculino adulto.

O aparato censor contava com muitos funcionários, de modo a evitar que qualquer elemento que atentasse contra a moral e os bons costumes fosse veiculado ao grande público. Além disso, nos pareceres foi possível observar o modus operandi da avaliação, que primeiramente era feita pelo técnico em censura, às vezes por mais de um, e com frequência revisados por supervisores, com a possibilidade de envio para análise superior. Os pareceres eram encaminhados ao SIGAB no caso de dúvidas sobre censura política, que fugia à alçada da DCDP.

Apesar da organização identificada no sentido de efetividade na proibição de circulação de conteúdo e imagens imorais, com a análise de toda a estrutura da revista, inclusive imagens publicitárias, verificou-se também certa falta de padronização nos termos e assuntos vetados ou liberados. Ou seja, apesar de todo o esforço da DCDP no controle moral sobre a publicação, existia no contexto da Homem certa permissividade, principalmente pelo entendimento de certos censores de que a revista tinha um público bem definido.

Mesmo com todo o aparato censor e o esforço na tentativa de impedir que determinados conteúdos circulassem e atentassem contra a moral e os bons costumes, a subjetividade presente no processo censório dava brechas para interpretaçáo do que se devia ou náo ser proibido. De modo que elementos que ora eram proibidos, em números subsequentes da revista eram permitidos.

\section{Fontes documentais}

A Revista do Homem, n. 13, 1976.

A Revista do Homem, n. 8, 1976.

BRASÍlLA (DF). Arquivo Nacional. Parecer [sem número], para A Revista do Homem [sem número]. 12 de novembro de 1975.

BRASÍliA (DF). Arquivo Nacional. Parecer [sem número], para A Revista do Homem n. 7. 22 de dezembro de 1975.

BRASÍlLA (DF). Arquivo Nacional. Parecer [sem número], para A Revista do Homem [sem número]. 8 de junho de 1976.

BRASÍLIA (DF). Arquivo Nacional. Parecer 4, para A Revista do Homem n. 7.5 de janeiro de 1976.

BRASÍLIA (DF). Arquivo Nacional. Parecer 11, para A Revista do Homem n. 7.7 de janeiro de 1976. 
A Revista do Homem (Playboy) e a Censura prévia Na ditadura militar (I975-I976):

ENTRE A MORAL, OS BONS COSTUMES E O HOMEM CONTEMPORÂNEO

Raphael Diego Greenhalgh e Carlos Henrique Juvêncio da Silva

BRASÍlIA (DF). Arquivo Nacional. Parecer 41, para A Revista do Homem n. 8. 20 de janeiro de 1976.

BRASÍlIA (DF). Arquivo Nacional. Parecer 184, para A Revista do Homem n. 10. 22 de março de 1976.

BRASÍlIA (DF). Arquivo Nacional. Parecer 234, para A Revista do Homem n. 11. 22 de abril de 1976.

BRASÍlIA (DF). Arquivo Nacional. Parecer 254, para A Revista do Homem [sem número]. 1976.

BRASÍLIA (DF). Arquivo Nacional. Parecer 283, para A Revista do Homem [sem número]. 26 de maio de 1976.

BRASÍlIA (DF). Arquivo Nacional. Parecer 339, para A Revista do Homem n. 13.24 de junho de 1976.

BRASÍlIA (DF). Arquivo Nacional. Parecer 354, para A Revista do Homem n. 13. 2 de julho de 1976.

BRASÍlIA (DF). Arquivo Nacional. Parecer 397, para A Revista do Homem n. 14.10 de agosto de 1976.

BRASÍlIA (DF). Arquivo Nacional. Parecer 413, para A Revista do Homem [sem número]. 31 de agosto de 1976.

BRASÍlIA (DF). Arquivo Nacional. Parecer 498, para A Revista do Homem n. 16-A e 17. 14 de outubro de 1976.

BRASÍLIA (DF). Arquivo Nacional. Parecer 574, para A Revista do Homem [sem número]. 24 de novembro de 1976.

BRASÍliA (DF). Arquivo Nacional. Parecer 623, para A Revista do Homem n. 19. 17 de dezembro de 1976.

BRASÍlIA (DF). Arquivo Nacional. Parecer 8.370, para A Revista do Homem n. 4.6 de outubro de 1975.

BRASÍlIA (DF). Arquivo Nacional. Parecer 9.187, para A Revista do Homem n. 5.3 de novembro de 1975.

BRASÍLIA (DF). Arquivo Nacional. Parecer 10.181, para A Revista do Homem n. 7.11 de dezembro de 1975.

BRASÍlIA (DF). Arquivo Nacional. Requerimentos para liberação da Revista do Homem. 1975-1976. Códigos de arquivamento: BR DFANBSB NS.CPR.PUB.198; BR DFANBSB NS.CPR.PUB.319.

RIO DE JANEIRO (RJ). Arquivo Nacional. Processo DICOM no 61.805. 1975-1976. Códigos de arquivamento: BR RJANRIO TT.0. MCP, PRO.436 
A Revista do Homem (Playboy) e a Censura prévia na ditadura militar (I975-I976):

ENTRE A MORAL, OS BONS COSTUMES E O HOMEM CONTEMPORÂNEO

Raphael Diego Greenhalgh e Carlos Henrique Juvêncio da Silva

\section{Referências}

BERG, Creuza. Mecanismos do silêncio: expressóes artísticas e censura no regime militar. 2. ed. Rio de Janeiro: Autografia, 2019.

BRASIL. Decreto-lei 1.077, de janeiro de 1970.

DOBERSTEIN, Juliano Martins. As duas censuras do regime militar: o controle das diversóes públicas e da imprensa entre 1964 e 1978. Dissertação (Mestrado em História) - Universidade Federal do Rio Grande do Sul, Porto Alegre, 2007. Disponível em: https://www.lume.ufrgs. br/bitstream/handle/10183/13815/000651661.pdf?sequence=1. Acesso em: 5 nov. 2019.

FURQUIM, Marcel Arruda. As representaçôes das masculinidades na Revista Playboy (Brasil) - 1978-1981. Dissertação (Mestrado em História) - Universidade Estadual Paulista, São Paulo, 2016. Disponível em: https://repositorio.unesp.br/bitstream/handle/11449/144711/ furquim_ma_me_assis.pdf?sequence=38isAllowed=y. Acesso em: 29 out. 2019.

GIORDANO, Verónica. Negócios, política e sexo - a revista Playboy do Brasil, 1975-80. Revista USP, São Paulo, n. 95, p. 150-158, set./nov. 2012. Disponível em: http:// www.revistas.usp.br/revusp/article/view/52247/56284. Acesso em: 28 out. 2019.

KUSHNIR, Beatriz. Cães de guarda: jornalistas e censores, do AI-5 à Constituição de 1988. São Paulo: Boitempo, 2012.

MARCELINO, Douglas Attila. Salvando a pátria da pornografia e da subversão: a censura de livros e diversóes públicas nos anos 1970. Dissertação (Mestrado em História Social) - Universidade Federal do Rio de Janeiro, Rio de Janeiro, 2006. Disponível em: http:// livros01.livrosgratis.com.br/cp069861.pdf. Acesso em: 29 out. 2019.

NAPOLITANO, Marcos. 1964: história do regime militar brasileiro. São Paulo: Contexto, 2014.

REIMÃO, Sandra. "Proíbo a publicação e circulação..." - censura a livros na ditadura militar. Estudos Avançados, São Paulo, v. 28, n. 80, p. 75-90, jan./abr. 2014. Disponível em: http://www.scielo.br/scielo.php?pid=S0103-40142014000100008\&script=sci_arttext. Acesso em 11 nov. 2019.

REIMÁO, Sandra. Repressáo e resistência: censura a livros na ditadura militar. São Paulo: Edusp, 2011.

RIBEIRO, Anderson Francisco. Desnudando a ditadura militar: as revistas eróticopornográficas e a construção da(s) identidade(s) do homem moderno (1964-1985). Tese (Doutorado em História) - Universidade Estadual Paulista, São Paulo, 2016. Disponível em: https://repositorio.unesp.br/handle/11449/141986. Acesso em: 28 out. 2019.

SIMÓES, Inimá. Roteiro da intolerância: a censura cinematográfica no Brasil. São Paulo: Editora Senac, 1999. 
A Revista do Homem (Playboy) e a Censura prévia na ditadura militar (I975-I976):

ENTRE A MORAL, OS BONS COSTUMES E O HOMEM CONTEMPORÂNEO

Raphael Diego Greenhalgh e Carlos Henrique Juvêncio da Silva

SMITH, Anne-Marie. Um acordo forçado: o consentimento da imprensa à censura no Brasil. Rio de Janeiro: Editora FGV, 2000.

VIEIRA, Nayara da Silva. Entre o imoral e o subversivo: a Divisão de Censura e Diversóes Públicas (DCDP) no regime militar (1968-1979). Dissertação (Mestrado em História Social) - Universidade de Brasília, Brasília, 2010. Disponível em: https://repositorio.unb. br/bitstream/10482/7002/1/2010_NayaradaSilvaVieira.pdf. Acesso em: 28 out. 2019. 